Revista de

Contabilidade e

Organizações

www.rco.usp.br
DOI: http://dx.doi.org/10.11606/rco.v8i22.61176
Journal of

Accounting and

Organizations

\title{
O desempenho dos profissionais de contabilidade no exame de suficiência do CFC: uma análise de conglomerados regionais
}

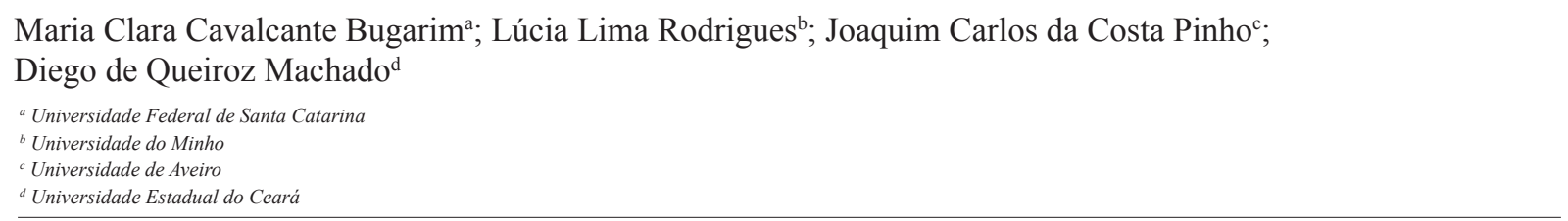

\section{Informações do Artigo}

Histórico do Artigo

Recebido: 14 de agosto de 2013

Aceito: 21 de novembro de 2014

Palavras chave

Contabilidade Brasileira

Exame de Suficiência

Conselho Federal de Contabilidade

Análise de Conglomerados.

\begin{abstract}
Resumo
Este estudo tem como objetivo analisar as características particulares de cada região do país, no que diz respeito aos resultados apresentados nos exames de suficiência do Conselho Federal de Contabilidade (CFC). Para tanto, foram considerados dados relativos ao desempenho dos candidatos em cada unidade federativa nas diferentes áreas de conhecimento que compõem o exame de suficiência. Os dados foram agrupados em dois momentos distintos: primeira fase do exame de suficiência, entre os anos de 2000 a 2004; e segunda fase do exame de suficiência, nos anos de 2011 e 2012. Esses dados foram analisados com aplicação do método estatístico multivariado de análise de conglomerados. A comparação dos resultados encontrados, principalmente em termos de composição dos grupos, mostra-se essencial para uma avaliação do desempenho desses profissionais no exame em cada uma das unidades federativas que compõem o Brasil. Além disso, os resultados deste estudo se constituem como um diagnóstico completo do desempenho no exame, apontando para áreas de maior fragilidade no ensino e que, para tanto, carecem ser mais bem exploradas na formação dos profissionais de Contabilidade.
\end{abstract}

Copyright (C) 2014 FEA-RP/USP. Todos os direitos reservados

\section{INTRODUÇÃO}

O ensino da ciência contábil está sempre se atualizando e se adaptando à realidade mundial. No Brasil, principalmente no século passado, a escola contábil passou por uma evolução sem precedentes, e agora, no século XXI, as instituições de ensino de Contabilidade têm o desafio de fornecer aos seus alunos uma educação de qualidade que acompanha as mudanças da economia globalizada.

Desde meados do século XX, quando surgiu o primeiro curso superior em Contabilidade, essa ciência vem sendo difundida em várias instituições de ensino superior pelo país, existindo, em 2009 (dados divulgados em 2010 pelo INEP), 922 cursos de graduação em ciências contábeis. Consoante a este panorama, o ensino de pós-graduação no Brasil também vem experimentando excepcional crescimento, o que representa um extraordinário ganho em qualidade profissional e acadêmica. $\mathrm{Na}$ área contábil, no entanto, esse fenômeno não vem ocorrendo em igual proporção. Sabe-se que o quantitativo de IES que realizam

Autor Correspondente: Tel + 5585 3477-3153

E-mail : mclara.bugarim@unifor.br (M. C. C. Bulgarim); lrodrigue@eeg. uminho.pt (L. L. Rodrigues); cpinho@ua.pt (J. C. C. Pinho); diegoqueirozm@yahoo.com.br (D. Q. Machado)

Universidade de Fortaleza - Av. Washington Soares, 1321 - 60811-905 Fortaleza-CE, Brasil cursos de mestrado e de doutorado em contabilidade está aquém das necessidades de um mercado cada vez mais competitivo. Dados da Associação Nacional dos Programas de Pós-Graduação em Ciências Contábeis (ANPCONT) revelam que existiam, até 31 de dezembro de 2009, 2.381 mestres e 191 doutores titulados, resultando em uma razão de em torno de 2 mestres ou doutores por curso de graduação.

Além disso, conforme investigou Moraes (2009), os mestres em contabilidade estão concentrados na região sudeste do país, especialmente no estado de São Paulo. Além disso, com exceção dos estados do Paraná e Santa Catarina, onde há dispersão de mestres em cidades do interior, nos demais estados onde há presença de mestres, estes estão concentrados nas capitais e respectivas regiões metropolitanas. Se do lado da oferta tem-se um número ainda pequeno de professores qualificados, no lado da demanda apresenta-se uma classe contábil que em setembro de 2012, chegou a 483.466 profissionais registrados, necessitando de qualificação para lidar com as novas realidades da profissão.

O Conselho Federal de Contabilidade (CFC), sempre preocupado em garantir à sociedade um profissional de qualidade, tem agido em diversas frentes implementando programas de fiscalização preventiva, de educação continuada e exames de certificação, dentre os quais o exame de suficiência, pré-requisito para registro profissional. Instituído em 1999, por meio da Resolução CFC n ${ }^{\circ} 853 / 99$, o exame de suficiência em Contabilidade 
consiste em uma prova em que todos os formandos no curso de bacharelado em Ciências Contábeis e no curso de técnico em Contabilidade precisariam se submeter para comprovar um nível médio de conhecimento para o exercício da profissão. No entanto, por ter sido criado atráves de resolução interna do CFC, esse exame foi suspenso no ano de 2005 a partir de uma medida judicial requerida pelo Ministério Público, alegando que tal exigência não posuía respaldo legal.

Após alguns anos de esforços para validar a exigência deste exame, alcançou-se o seu restabelecimento através da aprovação da Lei no 12.249 , de 11 de junho de 2010 . Assim, em março de 2011, o CFC voltou a aplicar o exame de suficiência. Ademais, sua importância é ressaltada por diversos autores, como Coelho (1999) e Madeira, Mendonça e Abreu (2003), que dão ênfase à utilização dos resultados do referido exame como indicadores de qualidade dos cursos de Contabilidade. Deste modo, reconhecendo a importância do exame de suficiência em Contabilidade como um instrumento para impulsionar a melhoria da qualidade do ensino ministrado na área, este estudo tem como objetivo analisar as características particulares de cada região do país, no que diz respeito aos resultados apresentados nos exames de suficiência do CFC.

Para tanto, foram considerados dados relativos ao desempenho dos candidatos em cada unidade federativa nas diferentes áreas de conhecimento que compõem o exame de suficiência. Os dados, fornecidos pelo próprio $\mathrm{CFC}$, foram agrupados em dois momentos distintos: primeira fase do exame de suficiência, entre os anos de 2000 a 2004; e segunda fase do exame de suficiência, nos anos de 2011 e 2012. Esses dados foram analisados com aplicação do método de análise de conglomerados, operacionalizados com o auxílio dos softwares de pequisa quantitativa IBM SPSS (versão 21) e Microsoft Excel (versão 2012).

\section{O EXAME NACIONAL DE SUFICIÊNCIA EM CONTABILIDADE}

No século XXI, a Contabilidade atravessa uma verdadeira revolução visando se adequar ao mundo globalizado. Após a Lei n ${ }^{\circ}$ 9.457/97, outras consideráveis alterações foram feitas à Lei das S.A. com o objetivo de alinhar as práticas contábeis brasileiras ao padrão internacional, como expõe Bacci (2002, p.144):

A contabilidade do mundo atual procura a harmonização de procedimentos, de padrões que atendam a globalização, e que pela pulverização dos investimentos a nível mundial nas bolsas de valores, vêm tentando uma uniformização dos informes contábeis com objetivos claros de se adotar maior transparência e evidenciação dos critérios aplicados.

Dessa forma, foi promulgada, em 2001, a Lei ${ }^{\circ} 10.303$, que altera e acrescenta dispositivos na Lei $\mathrm{n}^{\circ} 6.385 / 76 \mathrm{e}$ na Lei $n^{\circ} 6.404 / 76$, visando, principalmente, assegurar certos direitos dos acionistas e atrair investimentos no mercado de capitais. Dentre as mudanças apresentadas pela Lei $n^{\circ} 10.303$, destacam-se (Freire Filho, 2008):

a) somente os valores mobiliários de emissão de companhia registrada na Comissão de Valores Mobiliários podem ser negociados no mercado de valores mobiliários; b) nenhuma distribuição pública de valores mobiliários será efetivada no mercado sem prévio registro na Comissão de Valores Mobiliários;

c) o acionista controlador ou a sociedade controladora que adquirir ações da companhia aberta sob seu controle que elevem sua participação que impeça a liquidez de mercado das ações remanescentes será obrigado a fazer oferta pública para aquisição da totalidade das ações remanescentes no mercado;

d) o número de ações preferenciais sem direito a voto, ou sujeitas a restrição no exercício desse direito, não pode ultrapassar $50 \%$ (cinqüenta por cento) do total das ações emitidas; e

e) é vedado às companhias abertas emitir partes beneficiárias.

Com a finalidade de modernizar e harmonizar as disposições da lei societária brasileira com as melhores práticas internacionais, no último dia útil de 2007, 28 de dezembro, foi publicada a Lei $\mathrm{n}^{\circ} 11.638$, que reformulou a parte contábil da Lei das Sociedades por Ações (Lei $\mathrm{n}^{\circ}$ 6.404, de 15 de dezembro de 1976) visando atender à necessidade de maior transparência e qualidade das informações contábeis, em virtude da realidade econômica do Brasil e do mundo, com suas economias globalizadas e mercados abertos aos fluxos de capitais estrangeiros.

Após esse avanço ocorrido na Lei societária brasileira, tornava-se imprescindível também uma atualização na Lei de regência da profissão contábil, a qual já datava de mais de 64 anos e necessitava modernizar suas regras e assegurar mais qualificação aos profissionais contábeis. Assim, no dia 11 de junho de 2010, foi sancionada a Lei ${ }^{\circ} 12.249$ que dentre outras coisas, alterou diversos dispositivos constantes do Decreto-Lei $n^{\circ} 9.295 / 46$, regulador da profissão contábil. Dentre as principais mudanças trazidas pela aprovação da nova legislação, destacam-se:

Permite ao CFC regular acerca dos Princípios Contábeis, do exame de suficiência, do cadastro de qualificação técnica e dos programas de educação continuada; bem como, editar Normas Brasileiras de Contabilidade de natureza técnicas e profissionais (Art.76).

Dessa forma, com base nesse artigo e por meio da Resolução CFC nº53/99, foram considerados os seguintes aspectos para a implementação do exame de suficiência em Contabilidade (CFC, 2007):

a) $\mathrm{O}$ art. 12 do Decreto-Lei $\mathrm{n}^{\circ} 9,295$, de 27 de maio de 1946, que determina que o exercício da profissão de contabilista somente poderá ocorrer após o deferimento do registro profissional em Conselho Regional de Contabilidade;

b)A Aestrutura federativa do Conselho de Contabilidade, que coloca o Conselho Federal de Contabilidade investido na condição de órgão coordenador do Sistema $\mathrm{CFC/CRCs,} \mathrm{cabendo-lhe,} \mathrm{por} \mathrm{esse} \mathrm{motivo,} \mathrm{manter} \mathrm{a}$ unidade de ação;

c) A análise e a discussão da implantação do exame de suficiência durante anos nos eventos de contabilistas e de Contabilidade como uma necessidade decorrente do interesse da classe de resguardar a qualidade dos serviços prestados aos seus usuários;

d) $\mathrm{O}$ atendimento de um nível mínimo de conhecimento necessário ao desempenho das atribuições 
deferidas ao contabilista como objetivo do exame de suficiência;

e) $\mathrm{O}$ exame de suficiência como requisito para obtenção de registro profissional em CRC se reveste da função de fiscalização do exercício profissional, em caráter preventivo;

f) $\mathrm{O}$ inciso XXXII do art. 17 do Estatuto dos Conselhos de Contabilidade (Resolução CFC n ${ }^{\circ} 825 / 98$ ), que declara que ao CFC compete dispor sobre o exame de suficiência como requisito para a concessão de registro profissional.

Assim, a partir da instituição do exame do CFC, reconhece-se que para o exercício profissional de Contabilidade, o contador deve registrar-se no CRC, sendo que, para este registro ser obtido, a aprovação no exame de suficiência, aplicado desde então duas vezes ao ano, é obrigatória. Para ser aprovado no exame, o candidato ao registro profissional deve alcançar, no mínimo, $50 \%$ dos pontos possíveis na prova, conforme o artigo $5^{\circ}$ da Resolução CFC no 853/99. Neste sentido, observa-se que esta medida se constitui como uma tentativa do CFC de suprir algumas deficiências percebidas no ensino contábil, conforme apontadas por Iudícibus e Marion (1986), atendendo a uma necessidade de melhorias na qualidade dos serviços prestados por esses profissionais.

Corroborando com essa relação existente entre a aplicação do exame e melhorias no ensino contábil, Coelho (1999) assevera uma gradativa melhora no ensino em Contabilidade a partir da implantação do exame, que tem sua definição e implicações apresentadas pelo CFC da seguinte forma:

O Exame de Suficiência é a prova de equalização destinada a comprovar a obtenção de conhecimentos médios, consoante os conteúdos programáticos desenvolvidos no curso de bacharelado em Ciências Contábeis e no curso de Técnico em Contabilidade. Assim, poder medir a capacidade técnica mediana desse cidadão é dar-lhe o direito de saber quais são as suas condições técnicas para exercer a profissão. Com isso, vamos, teoricamente, possibilitar ao cidadão que ofereça à sociedade trabalhos mais qualitativas e que não se permita cometer infrações, $o$ que já seria, em parte, realização do cumprimento do dever dos Conselhos Regionais de Contabilidade de fiscalizar (CFC, 2007, p. 13).

Neste sentido, Madeira, Mendonça e Abreu (2003) também ressaltam a importância do exame de suficiência como um indicador de qualidade para os cursos de Contabilidade afirmando que:

Além de fornecer habilitação profissional, para o futuro registro, o Exame de Suficiência deveria servir como instrumento de apoio às instituições de ensino superior no processo de avaliação e acompanhamento dos cursos, pois através das provas é possível verificar os conteúdos exigidos e compará-los com aqueles ministrados nas faculdades. Dessa forma, seria possível identificar as prováveis deficiências, permitindo o aprimoramento dos cursos e, consequentemente, reduzindo as reprovações (Madeira, Mendonça e Abreu, 2003, p. 105).

No entanto, apesar dos benefícios atribuídos a instituição do exame do CFC, sua aplicação foi realizada apenas entre os anos de 2000 a 2004, sendo suspenso em 2005. Essa suspensão, segundo Lopes (2010), estaria relacionada com a quebra do Princípio Constitucional do Livre Exercício Profissional, pelo qual, conforme o inciso XIII do Art. 5 da Constituição Federal, afirma: "É livre o exercício de qualquer trabalho, ofício ou profissão, atendidas as qualificações profissionais que a lei estabelecer". Como a instituição do exame do CFC não se deu mediante lei específica, mas apenas através de resoluções do próprio conselho e outros atos normativos, entendeu-se que a sua obrigatoriedade era, dessa forma, inconstitucional.

Em 2010, através da Lei 12.249/2010 e Resolução CFC $\mathrm{n}^{\circ} 1.301 / 2010$, a obrigatoriedade do exame de suficiência é novamente instituída, agora amparada por lei específica. Desse modo, novamente são retomadas a aplicação das provas, duas vezes ao ano, sendo exigido dos candidatos o percentual mínimo de acerto de cinquenta por certo para aprovação no exame.

\section{METODOLOGIA DA PESQUISA}

Com o intuito de analisar as características particulares de cada região do país, no que diz respeito aos resultados apresentados nos exames de suficiência do CFC, esta pesquisa quantitativa se concentrará nos níveis das regiões e unidades federativas. Neste sentido, espera-se a observação de padrões de comportamento na variação dos resultados dos exames nas unidades federativas, assim como a busca de características comuns de comportamento.

Para tanto, foram considerados dados relativos ao desempenho dos candidatos em cada região nas diferentes áreas de conhecimento que compõem o exame de suficiência. Os dados históricos foram agrupados em dois momentos distintos: primeira fase do exame de suficiência, entre os anos de 2000 a 2004; e segunda fase do exame de suficiência, nos anos de 2011 e 2012. Assim, buscou-se perceber quais os padrões de comportamento das UFs em termos de resultados em cada área de conhecimento do exame, bem como analisar possíveis mudanças comparando o cenário construído nestes dois períodos históricos.

A fim de possibilitar uma abordagem estatística coerente com a proposta de investigação nesta fase da pesquisa, optou-se pela utilização da técnica de análise de conglomerados (cluster analysis). Conforme Corrar, Paulo e Dias Filho (2009, p. 325):

[...] é uma das técnicas de análise multivariada cujo propósito primário é reunir objetos, baseando-se nas características dos mesmos. Ela classifica objetos (p. ex., respondentes, produtos ou outras entidades) segundo aquilo que cada elemento tem de similar em relação a outros pertencentes a determinado grupo, considerando, é claro, um critério de seleção predeterminado. O grupo resultante dessa classificação deve então exibir um alto grau de homogeneidade interna (within-cluster) e alta heterogeneidade externa (between-cluster).

Sendo comumente utilizada em amostras populacionais, assim como grande parte das técnicas de estatística multivariada, esta técnica possui limitações quanto à inferência que pode ser feita dos grupos observados na amostra para a população geral (Corrar, Paulo e Dias Filho, 2009). Contudo, como neste estudo especificamente estão sendo trabalhados dados populacionais, relativos a todas as unidades federativas, esta limitação não é percebida, sendo os resultados atingidos representativos da população.

Além disso, também o problema da multicolinearidade, que, segundo Hair Jr., Anderson, Tatham e Black (2006), pode se apresentar quanto diversas variáveis integram um mesmo grupo de fatores, sendo desta forma, consideradas em conjunto, o que viria a interferir diretamente no resultado final dos grupos, 
não se mostra presente. Como neste estudo cada variável representa uma área de conhecimento e, dessa forma, uma dimensão diferente, não há interferências deste tipo de propriedade.

Ademais, conforme orientam Fávero, Belfiore, Silva e Chan (2009), esta técnica parte da análise das variáveis utilizadas para o agrupamento dos objetos. Como apresentado anteriormente, tais variáveis são os resultados atingidos pelos participantes no exame de suficiência em cada UF, sendo estes resultados divididos por área de conhecimento. Assim, sendo estas variáveis apresentadas em termos percentuais, outra vantagem de sua utilização nesta pesquisa é a ausência da necessidade de padronização dos dados, posto que todos se encontram dentro do mesmo padrão numérico.

\section{APRESENTAÇ̃̃O E ANÁLISE DOS RESULTADOS}

Tendo em vista analisar as características particulares de cada região do país, no que diz respeito aos resultados apresentados nos exames de suficiência do CFC, optouse pela aplicação da técnica de análise de conglomerados. Os resultados foram considerados no nível das unidades federativas e as variáveis escolhidas para esta análise foram os percentuais de acerto em cada área de conhecimento que constitui o exame de suficiência do CFC para os contadores, sendo elas: auditoria contábil (AUDI); contabilidade pública (PUBL); contabilidade de custos (CUST); contabilidade geral (GERA); contabilidade gerencial (GERE); legislação e ética profissional (LEGI); língua portuguesa (PORT); matemática financeira e estatística (MATE); noções de direito (DIRE); perícia contábil (PERI); princípios e normas (PRINC); teoria da contabilidade (TEOC). CSOC

A utilização dos percentuais de acertos em cada uma das áreas de conhecimento apresentada foi feita mediante cálculo das médias em dois períodos distintos: a primeira fase de aplicação do exame, entre os anos de 2000 a 2004; e a segunda fase de aplicação do exame, entre os anos de 2011 e 2012. Assim, a análise de conglomerados será aplicada para cada um dos dois períodos considerados, tendo em vista a possibilidade de observar mudanças no agrupamento dos casos entre os períodos. lém disso, vale ressaltar, que serão considerados todos e 26 estados e distrito federal que compõem o território nacional, não serão observados problemas em relação à representatividade da amostra, já que os casos observados fazem referência não a uma amostra de casos, mas a toda população. A seguir são apresentadas as análises estatísticas aplicadas em cada um dos períodos considerados.

4.1 Análise de conglomerados: primeira fase de aplicação do exame (2000-2004)

Inicialmente, a fim de verificar possíveis problemas de multicolinearidade entre as variáveis, o que poderia a afetar os resultados de agrupamento dos casos, optou-se pela realização de uma análise de correlação entre elas, conforme consta na Tabela 1, a seguir.

Tabela 1. Análise de Correlação das Variáveis no Período 2000-2004.

\begin{tabular}{|c|c|c|c|c|c|c|c|c|c|c|c|c|c|}
\hline & & $\overline{\mathrm{Q}}$ & $\stackrel{0}{2}$ & 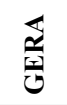 & 自 & 菅 & Ðુ & $\stackrel{5}{\Sigma}$ & 䆓 & $\frac{\bar{\alpha}}{\underline{\underline{c}}}$ & 占 & 壳 & ○ \\
\hline \multirow{2}{*}{ AUDI } & Pearson Corr. & 1 & ,637 &, 769 &, 726 &, 556 & ,631 &, 751 & ,484 & ,570 &, 481 &, 721 &, 518 \\
\hline & Sig. (2-tailed) & &, 000 &, 000 &, 000 &, 003 &, 000 &, 000 &, 011 &, 002 &, 011 &, 000 &, 006 \\
\hline \multirow{2}{*}{ CUST } & Pearson Corr. & ,637 & 1 & ,898 & ,919 & ,412 & ,482 & ,740 & ,302 & ,224 &, 342 & ,610 &, 397 \\
\hline & Sig. (2-tailed) &, 000 & &, 000 &, 000 &, 033 &, 011 &, 000 &, 125 & ,261 &, 080 &, 001 &, 040 \\
\hline \multirow{2}{*}{ GERA } & Pearson Corr. &, 769 & ,898 & 1 &, 862 &, 579 & ,688 &, 752 & ,488 & ,477 &, 421 &, 778 & ,477 \\
\hline & Sig. (2-tailed) &, 000 &, 000 & &, 000 &, 002 &, 000 &, 000 &, 010 &, 012 &, 029 &, 000 &, 012 \\
\hline \multirow{2}{*}{ GERE } & Pearson Corr. &, 726 & ,919 &, 862 & 1 &, 471 &, 484 &, 760 &, 325 &, 194 &, 500 &, 614 &, 374 \\
\hline & Sig. (2-tailed) &, 000 &, 000 &, 000 & &, 013 &, 011 &, 000 &, 098 &, 332 &, 008 &, 001 &, 055 \\
\hline \multirow{2}{*}{ PUBL } & Pearson Corr. &, 556 & ,412 &, 579 &, 471 & 1 &, 586 & ,494 &, 541 &, 349 &, 524 & ,632 &, 378 \\
\hline & Sig. (2-tailed) &, 003 &, 033 &, 002 &, 013 & &, 001 &, 009 &, 004 &, 074 &, 005 &, 000 &, 052 \\
\hline \multirow{2}{*}{ LEGI } & Pearson Corr. &, 631 &, 482 & ,688 &, 484 &, 586 & 1 &, 702 &, 547 &, 569 &, 723 &, 874 &, 650 \\
\hline & Sig. (2-tailed) &, 000 &, 011 &, 000 &, 011 &, 001 & &, 000 &, 003 &, 002 &, 000 &, 000 &, 000 \\
\hline \multirow{2}{*}{ MATE } & Pearson Corr. &, 751 &, 740 &, 752 &, 760 &, 494 &, 702 & 1 &, 493 &, 293 &, 616 &, 685 &, 328 \\
\hline & Sig. (2-tailed) &, 000 &, 000 &, 000 &, 000 &, 009 &, 000 & & ,009 &, 139 &, 001 &, 000 &, 095 \\
\hline \multirow{2}{*}{ DIRE } & Pearson Corr. &, 484 &, 302 &, 488 &, 325 &, 541 &, 547 & ,493 & 1 &, 428 &, 517 &, 643 &, 380 \\
\hline & Sig. (2-tailed) &, 011 &, 125 &, 010 &, 098 &, 004 &, 003 &, 009 & &, 026 &, 006 &, 000 &, 051 \\
\hline \multirow{2}{*}{ PERI } & Pearson Corr. &, 570 &, 224 &, 477 & ,194 &, 349 &, 569 & ,293 &, 428 & 1 &, 094 & ,644 &, 585 \\
\hline & Sig. (2-tailed) &, 002 & ,261 &, 012 &, 332 &, 074 &, 002 & ,139 &, 026 & &, 642 &, 000 &, 001 \\
\hline \multirow{2}{*}{ PORT } & Pearson Corr. &, 481 &, 342 &, 421 &, 500 &, 524 &, 723 &, 616 &, 517 &, 094 & 1 &, 671 &, 490 \\
\hline & Sig. (2-tailed) &, 011 &, 080 &, 029 &, 008 &, 005 &, 000 &, 001 &, 006 & ,642 & &, 000 &, 010 \\
\hline \multirow{2}{*}{ PRIN } & Pearson Corr. &, 721 &, 610 &, 778 &, 614 &, 632 &, 874 &, 685 &, 643 & ,644 &, 671 & 1 &, 784 \\
\hline & Sig. (2-tailed) &, 000 &, 001 &, 000 &, 001 &, 000 &, 000 &, 000 &, 000 &, 000 &, 000 & &, 000 \\
\hline \multirow{2}{*}{ TEOC } & Pearson Corr. &, 518 & ,397 & ,477 &, 374 &, 378 &, 650 &, 328 &, 380 &, 585 &, 490 & ,784 & 1 \\
\hline & Sig. (2-tailed) &, 006 &, 040 &, 012 &, 055 &, 052 &, 000 &, 095 &, 051 &, 001 &, 010 &, 000 & \\
\hline
\end{tabular}

Fonte: Dados da Pesquisa (2012). 
A partir da análise dos resultados da correlação entre as variáveis escolhidas para este estudo, observase que esses níveis de correlação são, em geral, baixos ou aceitáveis para o pressuposto de ausência de multicolinearidade entre essas variáveis. As exceções foram as correlações entre as variáveis GERA e CUST $(0,898)$, GERE e CUST $(0,919)$, GERE e GERA $(0,862)$, PRIN e LEGI $(0,874)$. Assim, apesar destes coeficientes apresentarem esta forte relação, como são poucos os casos em que este aspecto foi observado, optou-se pela não exclusão de nenhuma das variáveis.

Devido às suas vantagens, optou-se pela utilização do critério hierárquico de agrupamento complete linkage (vizinho mais distante), baseado na distância máxima entre os casos dentro de cada grupo. Sua vantagem, conforme apontam Corrar, Paulo e Dias Filho (2009), está em eliminar o problema da cadeia ou corrente prolongada, presente quando os objetos estão pobremente estruturados, formando longas cadeias com todos os indivíduos. Assim, sua utilização aumenta as chances de se obterem grupos mais equilibrados e menos dissimilares.

Para esta primeira análise, estabeleceu-se um intervalo de número de grupos aceitáveis com um mínimo de dois grupos e um máximo de cinco. Os resultados desta primeira solução são apresentados na Tabela 2, a seguir.

Tabela 2. Tabela de aglomeração do primeiro agrupamento (2000-2004).

\begin{tabular}{|c|c|c|c|c|c|c|}
\hline \multirow{2}{*}{ Stage } & \multicolumn{2}{|c|}{ Cluster Combined } & \multirow{2}{*}{ Coefficients } & \multicolumn{2}{|c|}{ Stage Cluster First Appears } & \multirow{2}{*}{ Next Stage } \\
\hline & Cluster 1 & Cluster 2 & & Cluster 1 & Cluster 2 & \\
\hline 1 & 13 & 21 & 002 & 0 & 0 & 6 \\
\hline 2 & 19 & 20 & 003 & 0 & 0 & 13 \\
\hline 3 & 14 & 15 & ,003 & 0 & 0 & 12 \\
\hline 4 & 5 & 6 &, 004 & 0 & 0 & 19 \\
\hline 5 & 7 & 10 & ,004 & 0 & 0 & 14 \\
\hline 6 & 13 & 17 &, 004 & 1 & 0 & 13 \\
\hline 7 & 16 & 25 & 004 & 0 & 0 & 8 \\
\hline 8 & 16 & 24 &, 006 & 7 & 0 & 21 \\
\hline 9 & 2 & 27 & 006 & 0 & 0 & 15 \\
\hline 10 & 9 & 12 & 007 & 0 & 0 & 11 \\
\hline 11 & 9 & 22 & ,007 & 10 & 0 & 18 \\
\hline 12 & 8 & 14 & 010 & 0 & 3 & 15 \\
\hline 13 & 13 & 19 & 010 & 6 & 2 & 19 \\
\hline 14 & 7 & 23 & 012 & 5 & 0 & 20 \\
\hline 15 & 2 & 8 & ,014 & 9 & 12 & 16 \\
\hline 16 & 2 & 4 & 016 & 15 & 0 & 21 \\
\hline 17 & 3 & 11 & 016 & 0 & 0 & 18 \\
\hline 18 & 3 & 9 & 024 & 17 & 11 & 22 \\
\hline 19 & 5 & 13 &, 024 & 4 & 13 & 20 \\
\hline 20 & 5 & 7 & 030 & 19 & 14 & 25 \\
\hline 21 & 2 & 16 & 033 & 16 & 8 & 22 \\
\hline 22 & 2 & 3 & 038 & 21 & 18 & 23 \\
\hline 23 & 2 & 18 &, 045 & 22 & 0 & 26 \\
\hline 24 & 1 & 26 & 077 & 0 & 0 & 25 \\
\hline 25 & 1 & 5 & 089, & 24 & 20 & 26 \\
\hline 26 & 1 & 2 & 204 & 25 & 23 & 0 \\
\hline
\end{tabular}

Fonte: Dados da Pesquisa (2012).

A partir dos critérios estabelecidos anteriormente, esta primeira análise agruparia as observações em dois grupos, sendo eles:

- Grupo 1 (12 casos): AC, BA, CE, DF, MA, MG, PE, RJ, RN, RS, RR, SE;

- Grupo 2 (15 casos): AL, AP, AM, ES, GO, MT, MS, PA, PB, PR, PI, RO, SC, SP, TO.

A escolha pela quantidade de dois grupos se deu mediante aplicação de um critério de parada simples, que considera os valores dos coeficientes entre as etapas, identificando momentos de elevação súbita. Percebe-se que da etapa 25 para a etapa 26 houve o maior aumento deste coeficiente $(0,089$ para 0,204$)$. Assim, a parada é indicada no estágio anterior a este aumento (etapa 25), onde a solução é de apenas dois grupos.

Processando uma análise de variância dos grupos (ANOVA) para verificar se existem diferenças significativas entre as variáveis, todas apresentaram níveis de significância inferiores a 0,05. Dessa forma, não se mostra necessária um novo processamento dos dados com diferentes variáveis.

Interpretando os dois grupos encontrados, observase que a solução bipartida contempla razoavelmente as diferenças entre os grupos, tendo em vista as distâncias entre os dois grupos. Essa distância pode ser observada no dendograma, apresentado na Figura 1, a seguir, onde se pode verificar que o Grupo 1 teve a sua interação com uma distância reescalonada de 11 , enquanto o Grupo 2 teve uma distância de 6 . 


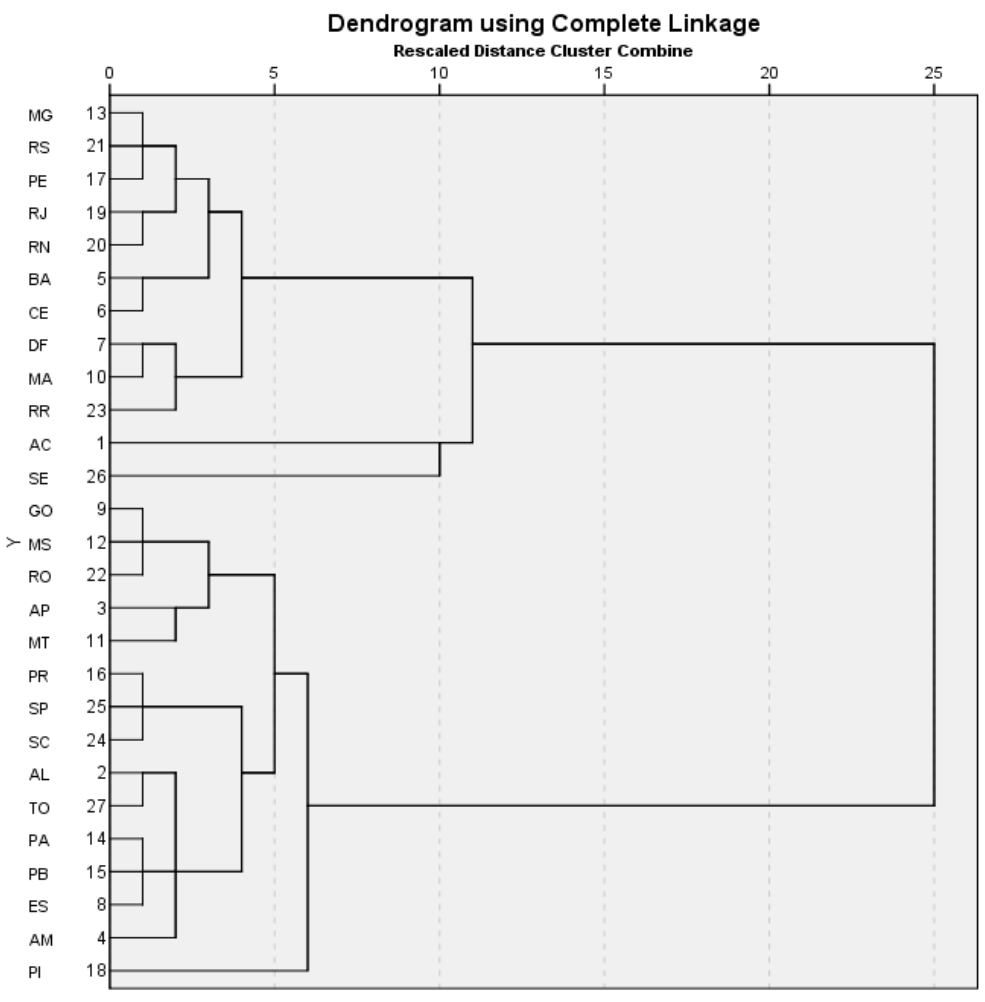

Figura 1. Dendograma (2000-2004).

Fonte: Dados da Pesquisa (2012).

O gráfico apresentado na Figura 2, a seguir, onde são apresentadas as médias de cada variável para os dois grupos permite visualizar as diferenças entre ambos. Essa diferença, conforme observado, relaciona-se mais com os resultados obtidos pelas unidades federativas em cada área de conhecimento do exame de suficiência do que em diferenças de padrões de resultados, já que as variações de resultados entre as variáveis são praticamente as mesmas, ficando o Grupo 1 com resultados superiores ao Grupo 2 em todas as áreas de conhecimento.

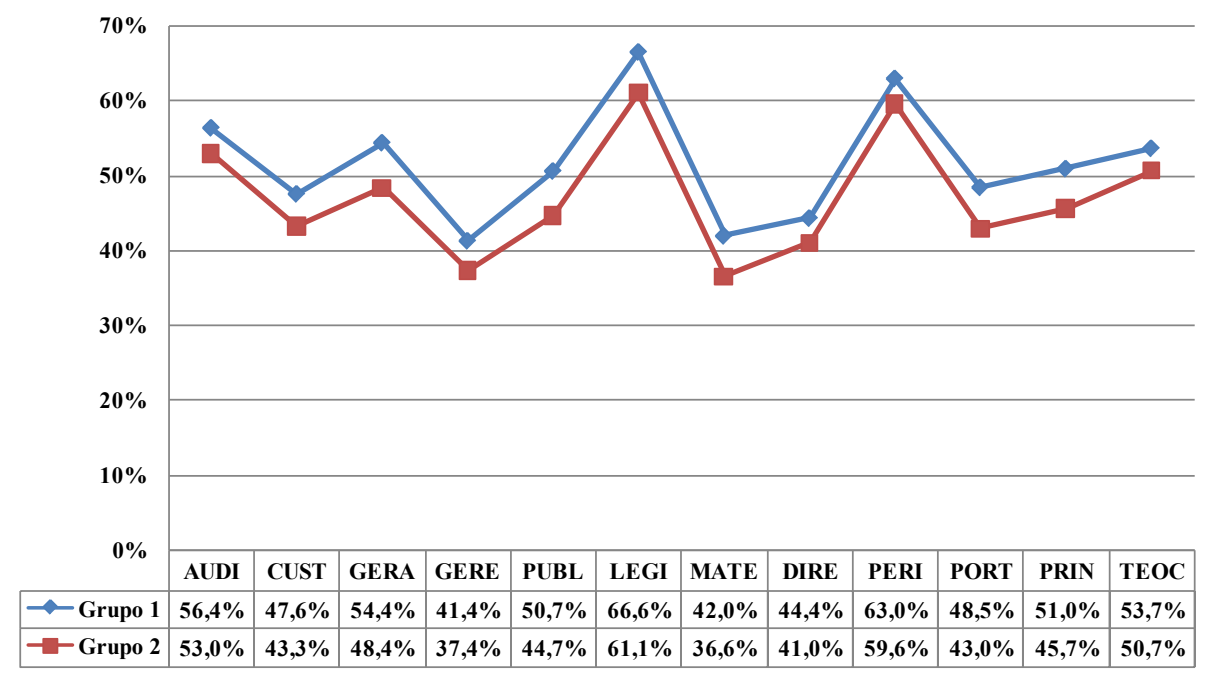

Figura 2. Diagrama de perfis das médias dos grupos (2000-2004).

Fonte: Dados da Pesquisa (2012). 
4.2 Análise de conglomerados: segunda fase de aplicação do exame (2011-2012)

Tendo em vista observar alterações nos padrões de agrupamento dos casos na nova fase de aplicação do exame, aplicou-se os mesmo procedimentos relativos à análise de conglomerados utilizados na investigação acerca da primeira fase e aplicação do exame (200020004) antes de sua suspensão.
Desse modo, nesta sessão, foram utilizadas as médias de acertos em cada área de conhecimento por unidade federativa, nas quatro edições do exame de suficiência, aplicadas no período de 2011 a 2012.

Em um primeiro momento, tendo em vista respeitar o pressuposto da ausência de multicolinearidade entre as variáveis, o que poderia a afetar os resultados de agrupamento dos casos, realizou-se análise de correlação entre as variáveis, conforme consta na Tabela 3, a seguir.

Tabela 3. Análise de Correlação das Variáveis no Período 2011-2012.

\begin{tabular}{|c|c|c|c|c|c|c|c|c|c|c|c|c|c|}
\hline & & $\stackrel{\Xi}{\Xi}$ & 占 & 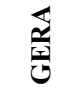 & $\frac{\text { 秃 }}{0}$ & $\overrightarrow{0}$ & $\underset{\Xi}{0}$ & $\frac{5}{\Sigma}$ & 寒 & $\frac{\bar{x}}{2}$ & 틍 & $\frac{\text { Z }}{\underline{a}}$ & $\begin{array}{l}\text { ○ } \\
\text { 됩 }\end{array}$ \\
\hline \multirow{2}{*}{ AUDI } & Pearson Correlation & 1 &, 850 &, 897 &, 878 & ,911 &, 834 &, 810 &, 773 &, 787 &, 887 &, 856 &, 853 \\
\hline & Sig. (2-tailed) & &, 000 &, 000 &, 000 &, 000 &, 000 &, 000 &, 000 &, 000 &, 000 &, 000 &, 000 \\
\hline \multirow{2}{*}{ CUST } & Pearson Correlation &, 850 & 1 & ,977 & ,976 & ,911 & ,705 & ,935 &, 744 &, 723 &, 774 &, 878 &, 891 \\
\hline & Sig. (2-tailed) &, 000 & &, 000 &, 000 &, 000 &, 000 &, 000 &, 000 &, 000 &, 000 &, 000 &, 000 \\
\hline \multirow{2}{*}{ GERA } & Pearson Correlation &, 897 & ,977 & 1 & ,981 & ,914 &, 744 & ,924 &, 743 &, 742 &, 839 & ,911 & ,918 \\
\hline & Sig. (2-tailed) &, 000 &, 000 & &, 000 &, 000 &, 000 &, 000 &, 000 &, 000 &, 000 &, 000 &, 000 \\
\hline \multirow{2}{*}{ GERE } & Pearson Correlation &, 878 & ,976 & ,981 & 1 & ,911 & ,759 & ,912 & ,711 &, 737 &, 825 &, 871 & ,904 \\
\hline & Sig. (2-tailed) &, 000 &, 000 &, 000 & &, 000 &, 000 &, 000 &, 000 &, 000 &, 000 &, 000 &, 000 \\
\hline \multirow{2}{*}{ PUBL } & Pearson Correlation & ,911 & ,911 & ,914 & ,911 & 1 & ,769 & ,859 &, 830 & ,749 & ,866 &, 859 &, 893 \\
\hline & Sig. (2-tailed) &, 000 &, 000 &, 000 &, 000 & &, 000 &, 000 &, 000 &, 000 &, 000 &, 000 &, 000 \\
\hline \multirow{2}{*}{ LEGI } & Pearson Correlation &, 834 &, 705 &, 744 & ,759 &, 769 & 1 & ,691 &, 567 &, 850 & ,792 &, 784 & ,809 \\
\hline & Sig. (2-tailed) &, 000 &, 000 &, 000 &, 000 &, 000 & &, 000 &, 002 &, 000 &, 000 &, 000 &, 000 \\
\hline \multirow{2}{*}{ MATE } & Pearson Correlation &, 810 & ,935 & ,924 & ,912 &, 859 & ,691 & 1 &, 710 &, 713 &, 761 &, 820 &, 819 \\
\hline & Sig. (2-tailed) &, 000 &, 000 &, 000 &, 000 &, 000 &, 000 & &, 000 &, 000 &, 000 &, 000 &, 000 \\
\hline \multirow{2}{*}{ DIRE } & Pearson Correlation &, 773 &, 744 &, 743 &, 711 &, 830 &, 567 &, 710 & 1 &, 575 &, 721 & ,676 &, 652 \\
\hline & Sig. (2-tailed) &, 000 &, 000 &, 000 &, 000 &, 000 &, 002 &, 000 & &, 002 &, 000 &, 000 &, 000 \\
\hline \multirow{2}{*}{ PERI } & Pearson Correlation &, 787 &, 723 &, 742 & ,737 & ,749 &, 850 &, 713 &, 575 & 1 & ,794 & ,694 &, 731 \\
\hline & Sig. (2-tailed) & 000 &, 000 &, 000 &, 000 &, 000 &, 000 &, 000 &, 002 & &, 000 &, 000 &, 000 \\
\hline \multirow{2}{*}{ PORT } & Pearson Correlation &, 887 &, 774 &, 839 &, 825 &, 866 &, 792 &, 761 &, 721 & ,794 & 1 &, 804 &, 854 \\
\hline & Sig. (2-tailed) &, 000 &, 000 &, 000 &, 000 &, 000 &, 000 &, 000 &, 000 &, 000 & &, 000 &, 000 \\
\hline \multirow{2}{*}{ PRIN } & Pearson Correlation &, 856 &, 878 & ,911 &, 871 &, 859 & ,784 &, 820 & ,676 & 694 &, 804 & 1 & ,914 \\
\hline & Sig. (2-tailed) &, 000 &, 000 &, 000 &, 000 &, 000 &, 000 &, 000 &, 000 &, 000 &, 000 & &, 000 \\
\hline \multirow{2}{*}{ TEOC } & Pearson Correlation &, 853 & ,891 & ,918 & ,904 &, 893 & ,809 & ,819 & 652 &, 731 &, 854 & ,914 & 1 \\
\hline & Sig. (2-tailed) &, 000 &, 000 &, 000 &, 000 &, 000 &, 000 &, 000 &, 000 &, 000 &, 000 &, 000 & \\
\hline
\end{tabular}

Fonte: Dados da Pesquisa (2012).

Diferente do observado no período anterior, a análise da correlação apresentou vários coeficientes de forte relação entre as variáveis. Contudo, como se sabe que cada uma dessas variáveis representa uma área de conhecimento que compõe o exame de suficiência, optou-se pela manutenção de todas as variáveis apresentadas. Ressalta-se que a variável CSOC, relativa ao percentual de acerto nas questões da área de conhecimentos sociais, não é utilizada nesta segunda fase da análise de conglomerados por não fazer mais parte do escopo do exame de suficiência. Assim como na análise anterior,utilizou-se o critério hierárquico de agrupamento complete linkage (vizinho mais distante), estabelecendose também um intervalo de número de grupos aceitáveis com um mínimo de dois grupos e um máximo de cinco. Os resultados desta primeira solução para o período 2011-2012 são apresentados na Tabela 4, a seguir. 
Tabela 4. Aglomeração do primeiro agrupamento (2011-2012).

\begin{tabular}{|c|c|c|c|c|c|c|}
\hline \multirow[b]{2}{*}{ Stage } & \multicolumn{2}{|c|}{ Cluster Combined } & \multirow[b]{2}{*}{ Coefficients } & \multicolumn{2}{|c|}{ Stage Cluster First Appears } & \multirow[b]{2}{*}{ Next Stage } \\
\hline & Cluster 1 & Cluster 2 & & Cluster 1 & Cluster 2 & \\
\hline 1 & 18 & 24 &, 001 & 0 & 0 & 4 \\
\hline 2 & 6 & 16 &, 001 & 0 & 0 & 5 \\
\hline 3 & 9 & 12 &, 001 & 0 & 0 & 19 \\
\hline 4 & 11 & 18 &, 002 & 0 & 1 & 8 \\
\hline 5 & 6 & 8 &, 002 & 2 & 0 & 17 \\
\hline 6 & 15 & 20 &, 002 & 0 & 0 & 15 \\
\hline 7 & 13 & 21 &, 002 & 0 & 0 & 9 \\
\hline 8 & 11 & 26 &, 002 & 4 & 0 & 17 \\
\hline 9 & 13 & 27 &, 003 & 7 & 0 & 16 \\
\hline 10 & 7 & 19 & ,004 & 0 & 0 & 13 \\
\hline 11 & 5 & 17 & ,004 & 0 & 0 & 20 \\
\hline 12 & 10 & 14 & ,004 & 0 & 0 & 16 \\
\hline 13 & 7 & 23 & ,005 & 10 & 0 & 23 \\
\hline 14 & 3 & 22 & ,005 & 0 & 0 & 18 \\
\hline 15 & 2 & 15 & ,005 & 0 & 6 & 20 \\
\hline 16 & 10 & 13 & ,007 & 12 & 9 & 19 \\
\hline 17 & 6 & 11 & ,007 & 5 & 8 & 21 \\
\hline 18 & 1 & 3 & ,007 & 0 & 14 & 22 \\
\hline 19 & 9 & 10 & ,008 & 3 & 16 & 24 \\
\hline 20 & 2 & 5 & ,009 & 15 & 11 & 25 \\
\hline 21 & 6 & 25 & 012 & 17 & 0 & 23 \\
\hline 22 & 1 & 4 & ,013 & 18 & 0 & 24 \\
\hline 23 & 6 & 7 & ,021 & 21 & 13 & 25 \\
\hline 24 & 1 & 9 & 024 & 22 & 19 & 26 \\
\hline 25 & 2 & 6 &, 041 & 20 & 23 & 26 \\
\hline 26 & 1 & 2 & ,148 & 24 & 25 & 0 \\
\hline
\end{tabular}

Fonte: Dados da Pesquisa (2012).

A partir dos critérios estabelecidos anteriormente, esta primeira análise agruparia as observações em dois grupos, sendo eles:

- Grupo 1 (16 casos): AL, BA, CE, DF, ES, MT, PB, PR, PE, PI, RJ, RN, RR, SC, SP, SE;

- Grupo 2 (11 casos): AC, AP, AM, GO, MA, MS, MG, PA, RS, RO, TO.

A escolha pela quantidade de dois grupos se deu pela aplicação do mesmo critério de parada simples, utilizado anteriormente. Neste caso, da etapa 25 para a etapa 26 houve novamente o maior aumento deste coeficiente $(0,041$ para 0,148$)$. Assim, a parada é indicada no estágio anterior a este aumento (etapa 25), onde a solução é de apenas dois grupos.

Processando uma análise de variância dos grupos
(ANOVA) para verificar se existem diferenças significativas entre as variáveis, todas apresentaram níveis de significância inferiores a 0,05. Dessa forma, não se mostra necessária um novo processamento dos dados com diferentes variáveis.

Interpretando os dois grupos encontrados, observase que a solução bipartida contempla razoavelmente as diferenças entre os grupos, tendo em vista as distâncias entre os dois grupos.

Essa distância pode ser observada no dendograma, apresentado na Figura 3, a seguir, onde se pode verificar que o Grupo 1 teve a sua interação com uma distância reescalonada de 7, enquanto o Grupo 2 teve uma distância de 4 . 


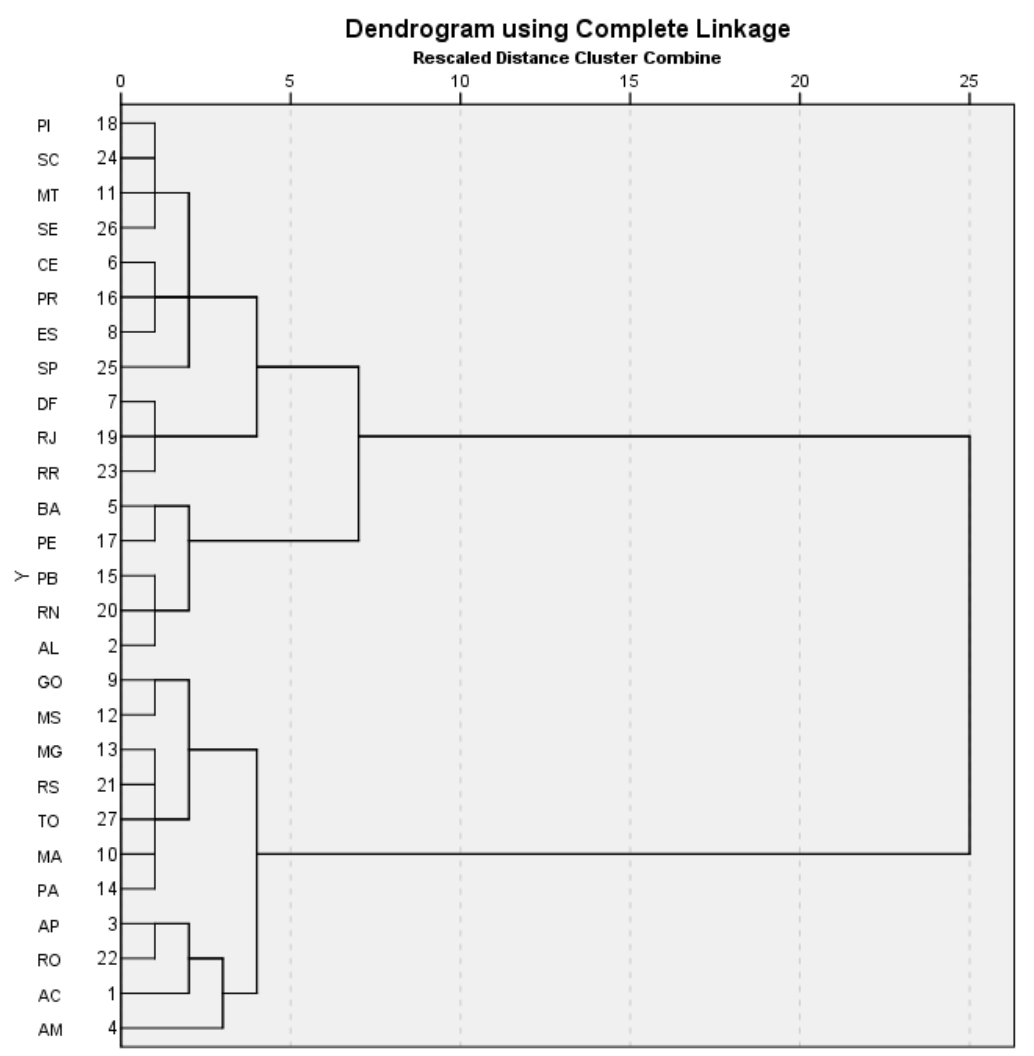

Figura 3. Dendograma (2011-2012)

Fonte: Dados da Pesquisa (2012).

Finalmente, o gráfico apresentado na Figura 4, a seguir, onde são apresentadas as médias de cada variável para os dois grupos permite visualizar as diferenças entre ambos.

Essa diferença, assim como observado no primeiro período de aplicação do exame, relaciona-se mais com os resultados obtidos pelas unidades federativas em cada área de conhecimento do exame de suficiência do que em diferenças de padrões de resultados, já que as variações de resultados entre as variáveis são praticamente as mesmas, ficando o Grupo $1 \mathrm{com}$ resultados superiores ao Grupo 2 em todas as áreas de conhecimento.

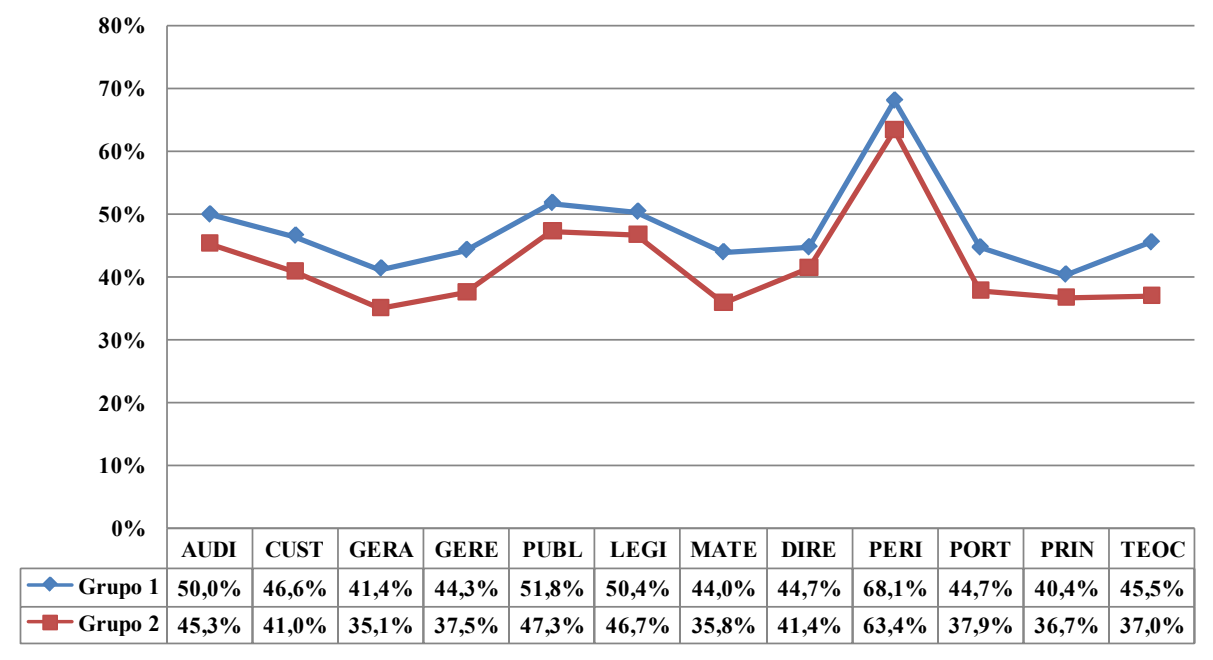

Figura 4. Diagrama de perfis das médias dos grupos (2011-2012).

Fonte: Dados da Pesquisa (2012). 


\subsection{Interpretação, classificação e perfis dos grupos}

A partir da aplicação da técnica de análise de conglomerados nos dois períodos de aplicação do exame de suficiência do CFC (2000-2004 e 2011-2012), foi possível apontar dois grupos em cada um dos períodos. O Quadro 1, a seguir, traz a composição de cada um dos grupos encontrados.

\begin{tabular}{|c|c|c|c|}
\hline \multicolumn{2}{|c|}{ Período 2000-2004 } & \multicolumn{2}{|c|}{ Período 2011-2012 } \\
\hline Grupo 1 (12 casos) & Grupo 2 (15 casos) & Grupo 1 (16 casos) & Grupo 2 (11 casos) \\
\hline $\begin{array}{c}01 \text { - Acre } \\
05 \text { - Bahia } \\
06 \text { - Ceará } \\
07 \text { - Distrito Federal } \\
10 \text { - Maranhão } \\
13 \text { - Minas Gerais } \\
17 \text { - Pernambuco } \\
19 \text { - Rio de Janeiro } \\
20 \text { - Rio Grande do Norte } \\
21 \text { - Rio Grande do Sul } \\
23 \text { - Roraima } \\
26 \text { - Sergipe }\end{array}$ & $\begin{array}{c}02 \text { - Alagoas } \\
03 \text { - Amapá } \\
04 \text { - Amazonas } \\
08 \text { - Espírito Santo } \\
09 \text { - Goiás } \\
11 \text { - Mato Grosso } \\
12 \text { - Mato Grosso do Sul } \\
14 \text { - Pará } \\
15 \text { - Paraíba } \\
16 \text { - Paraná } \\
18 \text { - Piauí } \\
22 \text { - Rondônia } \\
24 \text { - Santa Catarina } \\
25 \text { - São Paulo } \\
27 \text { - Tocantins }\end{array}$ & $\begin{array}{c}02 \text { - Alagoas } \\
05 \text { - Bahia } \\
06 \text { - Ceará } \\
07 \text { - Distrito Federal } \\
08 \text { - Espírito Santo } \\
11 \text { - Mato Grosso } \\
15 \text { - Paraíba } \\
16 \text { - Paraná } \\
17 \text { - Pernambuco } \\
18 \text { - Piauí } \\
19 \text { - Rio de Janeiro } \\
20 \text { - Rio Grande do Norte } \\
23 \text { - Roraima } \\
24 \text { - Santa Catarina } \\
25 \text { - São Paulo } \\
26 \text { - Sergipe }\end{array}$ & $\begin{array}{c}01 \text { - Acre } \\
03 \text { - Amapá } \\
04 \text { - Amazonas } \\
09 \text { - Goiás } \\
10 \text { - Maranhão } \\
12 \text { - Mato Grosso do Sul } \\
13 \text { - Minas Gerais } \\
14 \text { - Pará } \\
21 \text { - Rio Grande do Sul } \\
22 \text { - Rondônia } \\
27 \text { - Tocantins }\end{array}$ \\
\hline
\end{tabular}

Como observado anteriormente através dos diagramas de perfis das médias dos grupos em cada um dos períodos (Figura 14 e Figura 16), as unidades federativas integrantes do Grupo 1 são as que obtiveram conjunto de médias superiores quando comparadas às unidades que compõem o Grupo 2. Assim, pode ser perceber algumas mudanças entre os dois períodos analisados, bem como unidades que permaneceram no mesmo grupo em ambos os períodos. O Quadro 2, a seguir, apresenta uma classificação dessas unidades a partir da sua alocação e movimentação nos grupos entre os dois períodos comparados.

\begin{tabular}{|c|c|}
\hline $\begin{array}{c}\text { Comportamento nos } \\
\text { grupos }\end{array}$ & Unidades Federativas \\
\hline $\begin{array}{l}\text { Integrante do Grupo } 1 \\
\text { nos dois períodos }\end{array}$ & $\begin{array}{l}05 \text { - Bahia } \\
06 \text { - Ceará } \\
07 \text { - Distrito Federal } \\
26 \text { - Sergipe } \\
23 \text { - Roraima } \\
17 \text { - Pernambuco } \\
19 \text { - Rio de Janeiro } \\
20 \text { - Rio Grande do Norte }\end{array}$ \\
\hline $\begin{array}{l}\text { Integrante do Grupo } 2 \\
\text { nos dois períodos }\end{array}$ & $\begin{array}{l}03 \text { - Amapá } \\
04 \text { - Amazonas } \\
09 \text { - Goiás } \\
12 \text { - Mato Grosso do Sul } \\
14 \text { - Pará } \\
22 \text { - Rondônia } \\
27 \text { - Tocantins }\end{array}$ \\
\hline $\begin{array}{l}\text { Migrou do Grupo } 1 \\
\text { para } \\
\text { o Grupo } 2\end{array}$ & $\begin{array}{l}01 \text { - Acre } \\
10 \text { - Maranhão } \\
13 \text { - Minas Gerais } \\
21 \text { - Rio Grande do Sul }\end{array}$ \\
\hline $\begin{array}{l}\text { Migrou do Grupo } 2 \\
\text { para } \\
\text { o Grupo } 1\end{array}$ & $\begin{array}{l}02 \text { - Alagoas } \\
08 \text { - Espírito Santo } \\
11 \text { - Mato Grosso } \\
15 \text { - Paraíba } \\
16 \text { - Paraná } \\
18 \text { - Piauí } \\
24 \text { - Santa Catarina } \\
25 \text { - São Paulo }\end{array}$ \\
\hline
\end{tabular}

Quadro 2. Comportamento das Unidades Federativas nos períodos 2000-2004 e 2011-2012.

Fonte: Dados da Pesquisa (2012)
Reconhecendo o Grupo 1 como caracterizado pelas Unidades Federativas com maiores percentuais de acerto nas questões relativas às diversas áreas de conhecimento que compõem o exame de suficiência do $\mathrm{CFC}$, os casos que foram incluídos neste grupo nos dois períodos comparados são exatamente aqueles que não só apresentaram este desempenho superior nas primeiras dez edições do exame como mantiveram este nível de acerto nas últimas quatro edições. Ressalta-se que neste grupo, formado por oito unidades federativas, cinco são da Região Nordeste do Brasil (Bahia, Ceará, Sergipe, Pernambuco e Rio Grande do Norte).

Já o conjunto de unidades federativas que foram alocadas no Grupo 2, caracterizado como de menor desempenho relativo ao percentual de acertos no exame do CFC, em ambos os períodos analisados podem ser assinaladas como aquelas que têm apresentado um nível de acerto inferior, sendo esses estados integrantes das regiões Norte (Amapá, Amazonas, Pará, Rondônia e Tocantins) e Centro-Oeste (Goiás e Mato Grosso do Sul).

Ademais, foram observados estados que no período de 2000-2004 eram integrantes do Grupo 1, mas que no período de 2011-2012 foram transferidos para o Grupo 2. Esses estados, que são caracterizados por um decréscimo no percentual de acertos no exame de suficiência do CFC, foram os estados do Acre, Maranhão, Minas Gerais e Rio Grande do Sul.

Por fim, houveram estados que compunham o Grupo 2, de menor percentual de acertos, no período 2000-2004, e que foram alocados no Grupo 1, de maior percentual de acertos, no período 2011-2012, indicando uma melhora no seu desempenho. São os estados de Alagoas, Espírito Santo, Mato Grosso, Paraíba, Paraná, Piauí, Santa Catarina e São Paulo. 
Contudo, sobre essas alterações dos componentes de cada grupo entre os dois períodos, vale destacar que, como pode ser observado na comparação entre os valores médios apresentados nas Figuras 2 e 4, houve uma redução geral do desempenho das UFs ao longo das edições do exame. Assim, esse aumento ou redução de desempenho entre os períodos 2000-2004 e 2011-2012, que influenciou na composição dos grupos, é uma variável relativa que considera os resultados dos casos entre si. Ou seja, para os estados que migraram do Grupo 2 para o Grupo 1, essa melhora de desempenho é apenas relativa ao desempenho dos demais estados. Já para os estados que migraram do Grupo 1 para o Grupo 2, considera-se que esta redução no seu desempenho foi não apenas relativa aos demais estados, mas de forma geral.

\section{CONSIDERACÕES FINAIS}

Com o objetivo de analisar as características particulares de cada região do país no que diz respeito aos resultados apresentados nos exame de suficiência do $\mathrm{CFC}$, os resultados apresentados neste estudo ganham importância pelas implicações que trazem, tanto para as entidades de fiscalização, no caso, os Conselhos Federal e Regionais, quanto para as Instituições de Ensino Superior, que tem como missão formar profissionais capacitados para uma atuação satisfatória na sociedade.

A separação dos dados e de sua análise em dois momentos distintos - primeira fase de aplicação do exame entre os anos de 2000 a 2004 e segunda fase de aplicação do exame nos anos de 2011 e 2012 — pôde evidenciar mudanças relativas ao nível de desempenho dos candidatos em cada estado brasileiro.

Neste sentido, a comparação dos resultados encontrados na análise de conglomerados, principalmente em termos de composição dos grupos, torna-se essencial para uma avaliação do desempenho desses profissionais no exame em cada uma das unidades federativas que compõem o Brasil.

Além disso, como os resultados foram analisados não em termos de média de acertos no exame como um todo, mas considerando cada uma das áreas de conhecimento que o compõe, os resultados deste estudo se constituem como um diagnóstico completo do desempenho no exame, apontando para áreas de maior fragilidade no ensino e que, para tanto, carecem ser mais bem exploradas na formação dos profissionais de contabilidade, como Noções de Direito e Matemática Financeira.

Destarte, ressalta-se que este trabalho se constitui muito mais como uma construção exploratória do desempenho no exame do CFC por unidade federativa do que um quadro definitivo. Sendo assim, novas pesquisas que busquem uma apreciação mais específica, se possível dos resultados apresentados em cada uma das unidades federativas, assim como das diferenças em termos de ensino e formação entre esses estados, tornam-se necessárias para uma maior compreensão dos resultados aqui apresentados. Além disso, a realização de estudos que visem identificar as variáveis explicativas do desempenho desses profissionais no referido exame também se evidencia como essencial para auxiliar conselhos e instituições de ensino na construção de mecanismos que favoreçam o aprimoramento da formação do profissional contábil.

\section{REFERÊNCIAS}

ANPCONT. Quantidade de mestres e doutores em contabilidade. 2011. Disponível em: $<$ http://www. anpcont.com.br/site/materia.php?id=31>. Acesso em 28 ago. 2011.

BACCI, J. Estudo Exploratório sobre o Desenvolvimento Contábil Brasileiro - uma Contribuição ao Registro de sua Evolução Histórica. 2002. 175p. Dissertação (Mestrado em Controladoria e Contabilidade Estratégica)-Fundação Escola de Comércio Álvares Penteado, São Paulo.

BRASIL. Lei 9.457, de 5 de maio de 1997. Dispõe sobre alterações na Lei $n^{\circ} 6.404$ e na Lei ${ }^{\circ} 6.385$.

BRASIL. Lei 10.303, de 31 de outubro de 2001. Altera e acrescenta dispositivos na Lei no 6.404 .

BRASIL. Lei 11.638, de 2008 de dezembro de 2007. Dispõe sobre a adoção das IFRS.

BRASIL. Lei 12.249, de 11 de junho de 2010. Dispõe sobre a obrigatoriedade do Exame de Suficiência em Contabilidade.

COELHO, J. M. A. Exame de suficiência: um passo adiante. Revista Brasileira de Contabilidade, v. 28, n. $117,1999$.

CONSELHO FEDERAL DE CONTABILIDADE CFC. Caderno analítico do exame de suficiência: histórico dos resultados. Brasília: CFC, 2007.

CORRAR, L. J.; PAULO, E.; DIAS FILHO, J. M. Análise multivariada para os cursos de administração, ciência contábeis e economia. São Paulo: Atlas, 2009 .

FÁVERO, L. P.; BELFIORE, P.; SILVA, F. L.; CHAN, B. L. Análise de dados: modelagem multivariada para tomada de decisões. Rio de Janeiro: Elsevier, 2009.

FREIRE FILHO, M. R. Evidenciação dos conceitos 
e práticas de Governança Corporativa e Responsabilidade Social nas empresas mais antigas do Novo Mercado. 2008. Monografia (Graduação em Contabilidade) - Universidade de Fortaleza, Fortaleza.

HAIR JR., J. F.; ANDERSON, R. E.; TATHAM, R. L.; BLACK, W. C. Análise multivariada de dados. Porto Alegre: Bookman, 2006.

IUDÍCIBUS, S.; MARION, J. C. As faculdades de Ciências Contábeis e a formação do contador. Revista Brasileira de Contabilidade, v. 15, n. 56, p. $50-56,1986$.

LOPES, A. C. T. (2010). A ascensão e queda do exame de suficiência do CFC. Revista Contábil \& Empresarial Fiscolegis, 2010.

MADEIRA, G. J.; MENDONCA, K. F. C.; ABREU, S. M. A disciplina teoria da contabilidade nos exames de suficiência e provão. Contabilidade Vista \& Revista, v. 14, ed. especial, p. 103-122, 2003.

MEC. Sinopse da educação superior. 2010. Disponível em: http://portal.inep.gov.br/superiorcensosuperior-sinopse.

MORAES, R. O. Mestres em Ciências Contábeis sob a ótica do capital humano. São Paulo, 2009. Tese (Doutorado em Ciências Contábeis) - Programa de Pós-Graduação em Ciências Contábeis. Universidade de São Paulo. 